\title{
"Mercy above all" since 1922: a tribute to a hospital
}

\section{The Mustard Seed: The Story of St. Clare's Mercy Hospital}

Kathrine E. Bellamy RSM

Flanker Press; 2010.

$\mathrm{F}$ or the hospital historian, Newfoundland and Labrador offers a fascinating duality. Its insularity and prevailing social conditions have fostered various hospital "species," arguably more so than on the mainland. Yet, concurrently, it exists in the midst of several transoceanic routes that have permitted a high degree of interactivity with other populations that have influenced the evolution of these different hospitals.

The result is an astounding variety of hospitals. For example, the medical mission of the Englishman Sir (Dr.) Wilfred Grenfell - sponsored by international philanthropy - spawned nursing outposts and hospitals in the north. In the Notre Dame Bay area, the 1930s pioneering "socialist" system of medicare did much to keep the hospital working there (as did its cohort of American-trained doctors). A network of government-run "cottage hospitals" in the south and the west brought quality care to many in remote fishing outports, as did "floating" coastal hospital ships and clinics. While in the capital, St. John's, numerous military hospitals, a fever hospital, a tuberculosis sanatorium, a children's hospital, and an institution for "mental and nervous diseases" functioned. Also in St. John's, general hospitals operated along both nondenominational lines (the General) and religious lines such as the Grace (Salvation Army) and, the subject of this review, St. Clare's Mercy Hospital run by the Roman Catholic Order of the Sisters of Mercy, originally from Ireland.

In this respectful tribute to St. Clare's, The Mustard Seed, Sr. Kathrine Bellamy chronicles the hospital's development from its opening in 1922 with 20 beds, its growth to an institution of 375 beds

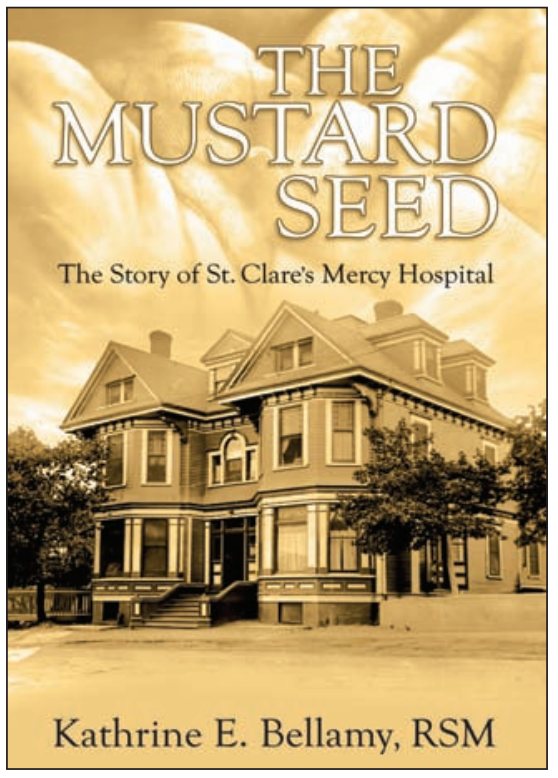

and its national recognition in 1992 by Chatelaine magazine as one of Canada's 12 "great" hospitals. Since 1842, the Sisters of Mercy had been ministering to the sick, poor and needy of St. John's, thus when this established tradition of care was redirected toward hospital patients it was not difficult for St. Clare's to live up to the motto "Mercy Above All." Accordingly, St. Clare's became home to Newfoundland's first alcohol and detoxification centre and its first palliative care unit, and absorbed the chronic care of tuberculosis patients following closure of the city's sanatorium; from 1922 until the obstetrics unit closed 70 years later, 83000 babies were delivered.

Bellamy's narrative occasionally echoes those of regional hospitals across Canada, but she astutely pays attention to particular politically based defining events. These include the legislated demise of the vital position of nurse-anesthetist in 1949 owing to Newfoundland's confederation with Canada; the introduction of salaries for nurses (religious sisters) in 1958-9 when federal hospital payments kicked in; and the struggle to retain the Roman
Catholic identity and culture of St. Clare's when it was required to corporatize/rationalize/amalgamate with other city institutions to create a secularized and centralized provincial regional health authority in the 1990s (but the buildings, name, and reputation carry on to the present).

The themes of cooperation and gender run through The Mustard Seed helping it cohere. Although the hospital founded its own nursing school in 1939, on many occasions it sent Sisters from Newfoundland to Baltimore's Mercy Hospital in Maryland for advanced training, or to "recruit" American counterparts for administrative posts for St. Clare's. That women should occupy the major role in the history of St. Clare's seems obvious; it wasn't that men (notably, doctors) weren't important, they just somehow seem irrelevant to this story. With the exception of the Archbishop of St. John's (and occasionally the Vatican) who had the ultimate (earthly) word, women ran this enterprise up and down, from stem to stern.

Understandably, Bellamy, who was an accomplished professional organist, notable choir director and music teacher, but not a medical historian, did not engage current hospital historiography. Her book nevertheless deserves a place on the historian's bookshelf; it is a useful addition to writings on nursing history and that of religious orders in Canada. The Mustard Seed also is a lasting tribute to the author herself for, just as the book was published, Sr. Kathrine Bellamy, aged 86, died in St. Clare's Mercy Hospital.

\section{J.T.H. Connor PhD}

John Clinch professor of medical humanities and history of medicine Faculty of Medicine Memorial University St. John's, NL

CMAJ 2011. DOI:10.1503/cmaj.101210 